\title{
Secção medular subtotal por ferimento de arma branca
}

\section{Section Subtotal for Spinal Cord Injury White Gun}

\author{
Pedro Manoel Gonzalez Cuellar ${ }^{1}$ Wilson Elias Oliveira Junior ${ }^{2}$ Filipe Carneiro de Queiroz ${ }^{3}$ \\ Leonardo Nunes de Castro Oliveira ${ }^{3}$ Pedro Henrique Lima Soares ${ }^{3}$
}

1 Professor Assistente da Universidade Federal do Tocantins (UFT), Preceptor do Programa de Residência Médica em Cirurgia Geral da Universidade Federal do Tocantins, Hospital Geral de Palmas (UFT-HGP), Palmas, TO, Brasil

2 Médico Residente do Programa de Residência Médica em Cirurgia Geral (UFT-HGP), Palmas, TO, Brasil

3 Interno do Curso de Medicina da UFT, Palmas, TO, Brasil

\author{
Address for correspondence Pedro Henrique Lima Soares, MD, \\ Universidade Federal do Tocantins, Coordenação do Curso de \\ Medicina. Av. NS 15, 109 Norte, Plano Diretor Norte, Palmas, \\ Tocantins, Brazil, CEP 77001-090 \\ (e-mail: pedrohenriquelimasoares@gmail.com). \\ Hospital Geral de Palmas, Palmas, TO, Brasil
}

Arq Bras Neurocir 2015;34:91-92.

\section{Resumo \\ Palavras-chave \\ - ferimentos perfurantes \\ - traumatismos da medula espinhal \\ - relato de caso}

Lesão de medula espinhal por arma branca é incomum, sendo responsável por 12\% dos traumas raquimedulares. Os autores descrevem um caso de secção de medula espinhal cervical subtotal por arma branca em um paciente de 18 anos.
Abstract
Keywords
- wounds stab
- spinal cord injuries
- case report

A spinal cord injury by stab is uncommon, accounting for $12 \%$ of spinal cord trauma. The authors describe a case of cervical spinal cord section subtotal stab wound in a patient of 18 years.

\section{Introdução}

O ferimento por arma branca (FAB) é um tipo de trauma comum no Brasil, principalmente no Norte e Nordeste. Os segmentos corporais mais acometidos são abdome, tórax e membros superiores. A seç̧ão da medula espinhal por FAB é pouco comum, porém acompanhada de grande risco de morte e prejuízo funcional a longo prazo para o paciente. ${ }^{1}$

Considerando a gravidade das lesões medulares causadas por FAB e a infrequência desse tipo de trauma, segue um relato de caso de secção medular cervical subtotal relacionado a esse tipo de acidente.

received

October 9, 2013

accepted

November 1, 2014
DOI http://dx.doi.org/ 10.1055/s-0035-1547389. ISSN 0103-5355.

\section{Relato do Caso}

Paciente masculino, 18 anos, pedreiro, procedente de Palmas/TO, admitido no Hospital Geral de Palmas consciente, orientado e verbalizando. Apresentou ferimento por arma branca em região cervical anterior e posterolateral esquerda (-Fig. 1), evoluindo com paresia e parestesia da região inferior do tórax, abdome e membros inferiores. Levado ao centro cirúrgico, foi submetido a cervicotomia exploradora da região anterior e posterior, sendo observada na região anterior lesão transfixante das veias jugulares superficiais, e na posterior, lesão perfurante de aproximadamente $2 \mathrm{~cm}$ de 


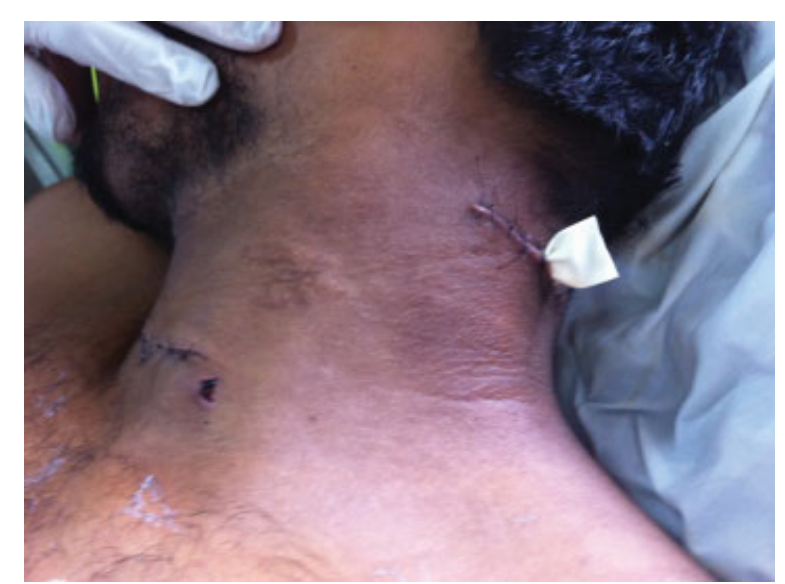

Fig. 1 Pós-operatório imediato com vista posteroanterior, demonstrando a lesão de entrada do ferimento na região posterior.

comprimento, que penetrava planos profundos, apresentando saída de líquor e caracterizando lesão medular. A tomografia computadorizada demonstrou lesão medular grave no nível das vértebras cervicais C5-C6, detalhada pela ressonância magnética que evidenciou secção medular cervical subtotal neste nível (-Fig. 2).

\section{Discussão}

Considerando-se a epidemiologia dos FAB, neste contexto, faz-se necessária a atenção a outras regiões corporais nas quais é infrequente esse tipo de trauma, mas que pode ser associado a grande morbimortalidade. A lesão da medula espinhal relacionada a este tipo específico de ferimento é pouco comum, correspondendo a aproximadamente $12 \%$ dos traumas raquimedulares. ${ }^{2}$ Nos ferimentos por arma branca da medula espinhal, as regiões mais acometidas em ordem decrescente são a coluna cervical, seguida pela torácica e lombar. O diagnóstico é dado pela história clínica associada ao exame neurológico do paciente. ${ }^{3}$ Para isso, faz-se a avaliação dos dermátomos e miótomos através de testes de sensibilidade epicrítica, protoprática, propriocepção e função motora. Exames de imagem como a tomografia e a ressonância magnética confirmam a lesão e dão a localização exata da mesma. Não existe um tratamento eficaz comprovado para casos de secção medular, mas o mesmo deve ter uma abordagem multidisciplinar envolvendo o tratamento cirúrgico, manejo das intercorrências clínicas, fisioterapia, cuidados de enfermagem específicos e apoio psicológico. ${ }^{4}$

Apesar de infrequente o trauma medular por arma branca é potencialmente grave a curto e a longo prazo,

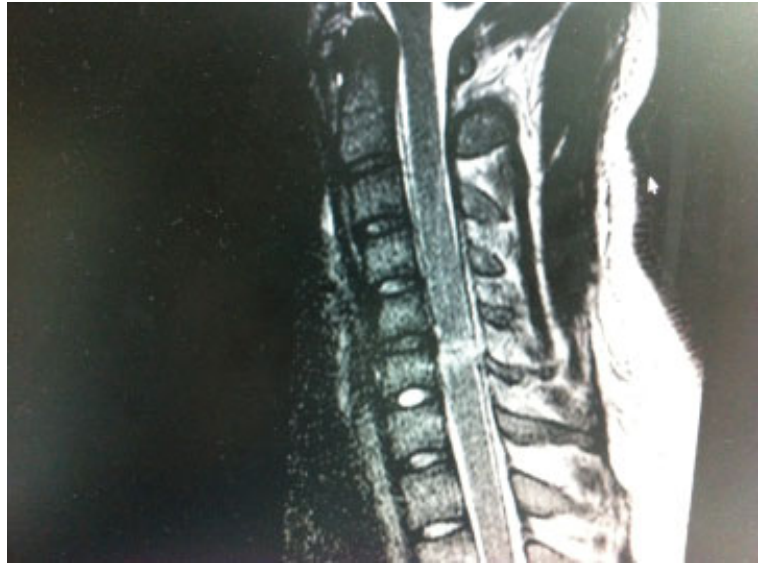

Fig. 2 Imagem de ressonância magnética, corte sagital em T2, evidenciando secção medular subtotal ao nível de C5-C6.

além de demandar elevados custos diretos e indiretos ao Sistema Único de Saúde. ${ }^{5}$ Existem poucos estudos na literatura nacional acerca desse assunto mostrando a necessidade de maior atenção a esse tema, possibilitando assim, a implementação de protocolos no manejo desses pacientes.

\section{Conflitos de Interesse}

Os autores declaram não haver conflitos de interesse.

\section{Referências}

1 Brito LM, Chein MB, Marinho SC, Duarte TB. Avaliação epidemiológica dos pacientes vítimas de traumatismo raquimedular. Rev Col Bras Cir 2011;38(5):304-309

2 Citadini JM, Scholtão J, Souza RB, Garanhani MR. Perfil epidemiológico dos pacientes com lesão medular do ambulatório de fisioterapia neurológica do Hospital Universitário Regional do Norte do Paraná. Londrina: Universidade Estadual de Londrina; 2003. Disponível em: http://www.ccs.uel.br/espacoparasaude/ vol5n1/PERFIl.pdf

3 Vasconcelos EC, Riberto M. Caracterização clínica e das situações de fratura da coluna vertebral no município de Ribeirão Preto, propostas para um programa de prevenção do trauma raquimedular. Coluna/Columna 2011;10(1):40-43

4 Custódio NR, Carneiro MR, Feres CC, et al. Lesão medular no Centro de Reabilitação e Readaptação Dr. Henrique Santillo (CRER-GO). Coluna/Columna 2009;8(3):265-268

5 Coura AS, França IS, Enders BC, Barbosa ML, Souza JR. Incapacidade funcional e associações com aspectos sociodemográficos em adultos com lesão medular. Rev Latino-Am Enfermagem 2012; 20(1):84-92 